\title{
Discourse Semantics Meets Lexical Field Semantics
}

\author{
Beate Firzlaff and Daniela S. Kunz \\ German National Research Center for Information Technology (GMD) \\ KONTEXT — Natural Language Systems \\ Dolivostr. 15 \\ D-64293 Darmstadt, Germany \\ \{firzlaff, kunz\}@darmstadt.gmd.de
}

\begin{abstract}
The focus of this article is the integration of two different perspectives on lexical semantics: Discourse Representation Theory's (DRT) inferentially motivated approach and Semantic Emphasis Theory's (SET) lexical field based view. A new joined representation format is developed which is exemplified by analyses of German verbs. The benefits thereof are on both sides. DRT gains basic entries for whole lexical fields and, furthermore, a systematic interface between semantic and syntactic argument structures. SET profits both from the much larger semantic coverage and from the fine grained lexical analyses which reflect inferential behaviour.
\end{abstract}

\section{Introduction}

The construction of lexical entries is one of the crucial and challenging tasks given in the ficld of computational linguistics. In the ideal case, lexical entries fulfill, among others, two requirements. First, the representations are suitably fine grained such that they capture lexeme-specific distinctions. Second, the lexical entries are sufficiently general for reflecting similarities between single lexemes. Furthermore, the information they contain should systematically link various levels of description, c.g. syntax and semantics as well as referential and inferential potential. The latter is of special interest for text analysis as opposed to sentence analysis (cf. for example (Hacnelt, 1994); (Haenelt and Könyves-Tóth, 1991)).

Corresponding to these requirements, we exploit the specific strengths of two distinct semantic theories. These theories are Discourse Representation Theory (DRT) ((Kamp and Reyle, 1993); (FraCaS-D8, 1994)) and Semantic Emphasis Theory (SET) ((Kunze, 1991); (Kunze, 1993)).
However, our central goal is an integration of DRT and SET. It will be shown that this integration is possible and of benefit to both theories as well as to the construction of lexical entries. To achieve our overall objective, the following four points will be exemplified by joined representations of German verbs:

- DRT profits from SET's systematic derivations of thematic roles and of morpho-syntactic features on the basis of predicate-argumentstructures. These features include both grammatical and prepositional case.

- DRT gains a purcly semantically motivated oricntation towards lexical fields.

- DRT covers much more semantic phenomena than SET. Therefore, DRT offers SET the possibility to test its results against a semantic background that e.g. includes plurals, tenses, and attitudes.

- DRT's fine grained lexical analyses are grounded in inferential behaviour. These lexical distinctions mark possible starting points for refining SET's representations.

The paper is structured as follows: DRT's and SET's basic motivations, principles and formal means concorning loxical somantics are retraced in sections 2 and 3 . The new joined representation format is introduced in section 4 by analysing the German verbs leihen (in its variant to lend) and verschenken (in its variant to give as a present). Moreover, section 4 provides evidence that tho four main points stated above are backed up by the joined analyses. Finally, directions for further research are pointed out in section 5 .

\section{DRT - Inferentially Motivated}

Discourse Representation Theory (DRT) is first and foremost a theory about discourse interpretation, i.e., it is essentially textually oriented in nature. The meaning of sequences of sentences is seen as strongly connected with their 
inferential behaviour. Therefore, work on lexical semantics in the DRT framework ((Kamp) and Roßcleutscher, 1994a); (Kamp and Roßcleutscher, 1994b); (Roßdeutscher, 1994)) investigates the role of lexical information in supporting inferences. Consequently, lexical distinctions correlate with non-cquivalent sets of associated inferences.

The following examples illustrate that the German verb leihen (in its variant to lend) implies in contrast to the German verb verschenken (in its variant to give as a present) the lending person's belief in a return of the involved object:

(la) Calvin leiht Hobbes eine Krawatte. (Calvin lends Itobbes a tic)

$$
\Longrightarrow
$$

(1.b) Calvin glaubt, dajs Hobbes ihm die Krawatte zuriüekgeben wird. (Calvin believes that Hobbes him the tie will give back)

(2a) Calvin verschenkt ein Buch an Iobbes. (Calvin gives as a present a book to Hobbes) $\stackrel{? ? ? ?}{?}$

(2b) Calvin glaubt, daß Kobbes ihm das Buch zurückgeben wird. (Calvin belicves that Hobbes him the book will give back)

In line with the representation format developed by Kamp and RoBdentscher, the corresponding lexical entries are twofold structures: They consist of a presuppositional and an assertoric Discourse Representation Structure (I)RS). 'Ihe underlying anaphoric notion of presupposition was originally proposed by (Sandt, 1992). Presuppositional information is embedded in the discourse context by a process called justification, which combines binding (verification) with contextilal enrichmont (accommodation) in varying proportions.

Kamp and Roßdeutscher model the interface between syntactic and semantic arginnents as a list of pairs. Each pair consists of tho generalized case information and the corresponding thematic role of the argument slot under consideration. This mapping offers two starting points for an integration of DRT and SET.

Firstly, the representation format for the generalized case information is only skotched, an algorithm for case assignmont is not given: With each verb is associated a given set of so-called theta roles $\theta_{i}$. These theta roles are arranged in a fixed hierarchy, the theta-hierarchy. [...] Those argument phrases which get assigned a theta role also get assigned a particular case (Nom, Acc, etc.). [...] Case assignment is partially determined by the theta hierarchy in that the argument phrase which bears the highest theta role (in the sonse of this hierarchy) aluays gets nominative case. ((Kamp and RoBdeutscher, 1994a): pp. 109f)
Secondly, the thematic roles are specified individually for each lexical entry, there is no generalization with respect to lexical fields. As an example, the interface list of verschenken is given in Figure 1, where the components of each pair are displayed vertically.

$$
\left[\begin{array}{c}
\left\langle\theta_{1}, \text { NOM }><\theta_{2}, \Delta C \mathrm{C}>\left(<\theta_{3}, \text { an }+ \text { GCO }>\right)\right. \\
\text { Agent\&Source 'Therime }
\end{array}\right]
$$

Figure 1. Interface list of verschenken.

The discourse referent ec and the thematic roles of the interface are direct, links to the DRS representing the meaning of the German verb verschenken (cf. Figure 2). The event complex ec, which stiands for the verb itself, is described as a process $e$, which is caused by an action $e^{\star}$ of a person p. $p$ represents the one who gives the present, $u$ to another person $q$. 'The giving itself is characterized by the concept CIANGF-SIGN. The signs changed are those of the disposal and owner. ship relations $s_{0}$ and $s_{1}: p$ looses the disposal and ownership of $u$ and $q$ gains them. The former circumstances of disposal and ownership ( $s_{0}$ and $s_{1}$ abut on $e c: s_{0} \supset$ X $\left.e c: s_{1} \chi^{\circ} e c\right)$ are presupposed, the poststiates (ec $\supset s_{2}$ ec $\left.\supset s_{3}\right)$ are asserted.

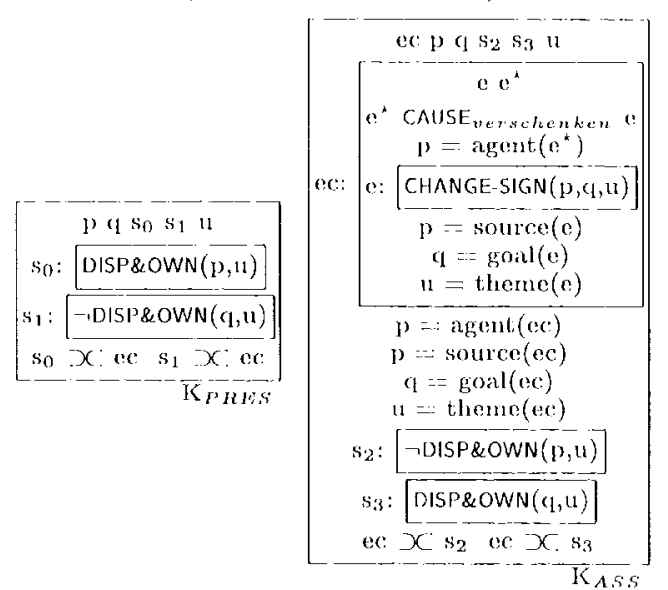

Figure 2. DRS of verschenken.

The example inferences (1a) to (1b) and (2a) to (2b) result from differences in the lexical DIRSs of leihen and verschenken. The main point hore is that the German verb leihen implies the londing person's belief in a return of the involved object. On the basis of this belief it is easy to infer from (1a) to (1b). However, there is no similar support, for inferring from (2a) to (2b). A detailed lexical representation of leihen will be given in section 4 .

\section{SET - Lexical Field Based}

Semantic Fmphasis Theory (SET) has identified principles that allow to link a prototypical description of a situation to a number of prototypical meaning descriptions of concrete lexemes 
that are suitable to refer to that situation. The link is based on a set of well-defined and systematically occurring mappings (cf. (Firzlaff and Kunze, 1995)) rather than on intuitive criteria. Given a basic semantic form (BSF) as a common starting point, we derive semantic and syntactic case frames and construct prototypical meaning descriptions of concrete lexemes by refining the BSF. Additionally, the rule based interpretation of a BSF delivers a prototypical description of the corresponding situation.

The set of lexemes that are suitable to refer: to the same situation constitutes a lexical field. The field as a whole is characterized by a BSF. A BSF is a propositional description. It consists of a predicate and a number of arguments, each of which is either a predicate-argument structure or an clementary argument. In general, elementary arguments are represented by variables that have to be filled in by phrases which denote reference objects (participants of a situation).

The number of arguments, as woll as the decision whether the arguments are elementary or propositional, both depend on the predicate that, directly takes these arguments. We derive the participants' thematic roles (deep cases) in accordance with a set of general rules. Scmantically, each pair of a role and the predicate directly dominating an elementary argument demands particular selectional features for that argument. The $\mathrm{BSF}$ describing the field of change-of-possession (with one object to be transferred) and the derived deep cases are given in Figure 3 .

\begin{tabular}{|c|c|}
\hline CAUSE & $\mathrm{r}:\langle$ agens,act $\rangle$ \\
\hline$(\mathrm{ACT}(\mathrm{r})$ & p: (source,have $)$ \\
\hline ET & c: (goal, have \\
\hline$(\operatorname{BEC}(\operatorname{NOT}(\operatorname{HAVE}(p, u)))$ & $\mathrm{u}:\langle$ from-obj, have $\rangle$ \\
\hline $\operatorname{BEC}(\operatorname{HAVE}(\mathrm{q}, \mathrm{u}))))$ & 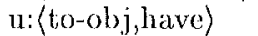 \\
\hline
\end{tabular}

Figure 3. BSF and deep cascs.

From both the syntactic and the semantic point of view, the BSF delivers tho maximum case frame of the lexemes that constitute the lexical field. Some of the roles of the maximum case frame can be put into the foreground; these are said to have cmphasis. Some roles must not be verbalized explicitly; these are said to be blocked. In the subset of roles that are not blocked there are, on the one hand, roles referring to obligatory actants and, on the other hand, roles referring to optional actants. Which roles have emphasis and which do not have emphasis, which are the ones that must be verbalized, and which are the ones that need not be verbalized is determined according to general rules. Exploiting the field specific possibilities to make some variables denote the same reference object (by renaming of variables) results in more specific
BSF's. These then describe partial lexical fields like, e.g. to give or to take.

By adding information about emphasis and blocking of roles, a BSF is transformed into a number of prototypical meaning descriptions. We can then derive systematically which are the suitable grammatical realizations of each role. However, there are two important points concorning the determination of which grammatical realizations are possible: Firstly, the predicate that takes the corresponding clementary argument directly and, secondly, the choice of that subset of roles of the maximum case frame that are not blocked. One of the three prototypical meaning descriptions that constitute the partial field of to give and the grammatical case assignmont of verschenken ${ }^{1}$ is given in Figure 4. (Those parts of the description that have emphasis are written in bold face. The occurence of a variable preceded by " $\gamma$ " is blocked. The grammatical realization of the optional actant $($ antaccusative $)$ is put in brackets. $\left.{ }^{2}\right)$

\section{CAUSE}
(ACT $(p)$
$\langle$ agens,act 〉: nom

ET

(BEC (NOT(HAVE $(\gamma \mathbf{p}, \mathbf{u})))$ (from-obj, have $\rangle$ : acc
BLC

$$
(\operatorname{HAVE}(q, \gamma \mathbf{u})))) \quad\langle\text { goal,have }):(\text { ant }+ \text { acc) }
$$

e.g.: Calvin verschenkt ein Buch an Hobbes

(Calvin gives as a present a book to Hobbes)

[ pnom

uace qan+acc ]

Figure 4. Prototypical meaning description and grammatical case assignments.

However, BSFs do not only provide the ground for the derivation of grammatical features. They are also suitable to derive prototypical situation descriptions. In order to do so, instantiation rules must be applied to a BSF in a recursive way. The application of instantiation rules has to be regarded as an interpretation of every partial description in a BSF. Some of these parts are then represented by variables that have to be filled in by objects referring to states or events, and other parts deliver relationships between these states or cvents. In addition, some of the instantiation rules provide temporal and/or spatial constraints that are applicable to (the corresponding parts of) a prototypical situation description, c.g., etime is a mapping from the set of events or states to the set of temporal entities (etime: $\mathcal{E} \rightarrow \mathcal{T}$ ).

In general, the instantiation rules provide struc-

\footnotetext{
${ }^{1}$ Generally, this grammatical case assignment is suitable for about 20 verbs of the partial field to give.

${ }^{2}$ More precisely, there is a mapping from the set of variables into the set of nominal phrases (more generally, parts of speech) $\mathrm{f}: \mathcal{V} \rightarrow \mathcal{F}$.
} 


\begin{tabular}{|c|c|c|c|}
\hline & & Presuppositions: & Assertions: \\
\hline $\begin{array}{l}\text { CAUSE } \\
\left(\Lambda C^{\prime} \Gamma(p)\right.\end{array}$ & e: & $\operatorname{ref}(f(p))$ : theme-act & 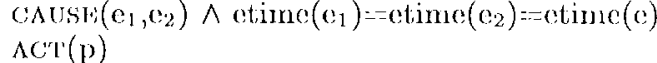 \\
\hline E'T & $\mathrm{C}_{2}:$ & 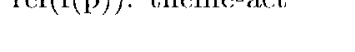 & $\left(\mathrm{c}_{21}, \mathrm{e}_{22}\right) \wedge \operatorname{etime}\left(\mathrm{c}_{21}\right)=\operatorname{etime}\left(\mathrm{e}_{22}\right)=\operatorname{etime}\left(\mathrm{c}_{2}\right)$ \\
\hline$(\mathrm{BLC}$ & $e_{21}:$ & $\begin{array}{l}\operatorname{ref}(f(p)): \text { locat-have: } \\
\wedge \operatorname{rof}(f(u)): \text { theme-have }\end{array}$ & TRANSITION (init $\left(\mathrm{c}_{21}\right)$, firl $\left.\left(\mathrm{c}_{21}\right)\right)$ \\
\hline$\left(\mathrm{NO} \mathrm{I}^{\prime}(\mathrm{H} \Lambda \mathrm{VF}(\mathrm{p}, \mathrm{u}))\right)$ & $\begin{array}{l}\operatorname{init}\left(c_{21}\right): \\
\text { finl }\left(c_{21}\right):\end{array}$ & $\operatorname{IIAVIS}(\mathrm{p}, \mathrm{u})$ & $\because \ln \cup \mathrm{Q}(\mathrm{p}, \mathrm{ul})$ \\
\hline BEC & $\mathrm{c}_{22}:$ & $\begin{array}{l}\operatorname{ref}(f(q)): \text { locat-have } \\
\wedge \operatorname{rof}(f(u)): \text { theme-have }\end{array}$ & TRANSITION (init $\left.\left(e_{22}\right), f \operatorname{in}\left(e_{2,2}\right)\right)$ \\
\hline$(\operatorname{IIAVL}((q, 1))))$ & $\begin{array}{l}\operatorname{init}\left(\mathrm{c}_{22}\right): \\
\operatorname{fin}\left(\mathrm{c}_{22}\right):\end{array}$ & $-\neg \operatorname{ll} \Lambda V \operatorname{li}(\mathrm{q}, \mathrm{u})$ & $\operatorname{IIAVES}(4, u)$ \\
\hline
\end{tabular}

Figure 5. IBSF and prototypical situation description.

toring mechanisms in terms of presuppositions and assertions. As an example, consider the predicate BBAC: It has one argument which is a predicate-argunent-structure. This structure is to be interpreted as the final state of a transition. Becanse of the instantiation rule of $13 \mathrm{HC}$ the initial state (init(e)) of the transition (e) is the "opposite" of the final state (fin (e)), i.e., $B L C(\Lambda)$ is interpreted as e: 'IR $\Lambda$ Nsrron $(\neg \Lambda, \Lambda)$. According to (Jung and Küstner, 1990), init (e) (i.e. $-\Lambda$ ) is the presupposition of $e$, and "-, does not affect $\Lambda$ 's presupposition, e.g. selectional restrictions for A's elementiary arguments. $\Lambda$ more extensive cxarnple of the derivation of prototypical situation descriptions is given in l'igure $5 .^{3}$

'Tho situation prototypically described in lig'ure 5 can be refered to by about 65 German verbs, i.e., the elements of the partial ficld to give including our sample verbs verschenken (in its variant to give as a present) and leihen (in its variant to lend). $\Lambda$ s far as the degree of specification is concerned the description is at least suitable as common denominator. Since SlT"s principal orientation is towards the systematic description of lexical fields rather than of singlo lexieal contries, it provides representidions which tend to be underspecified with respect to e.g. DRrT"s requirements. However, due to SEI"s general approach any further specification of its descriptions leads to an enlargement of the representation rather than to a change of the common denominator. The deseriptions provided by SET are suitable as the basis for fine grained representations. Therefore, one can expand the lexical entries rather than constructiing them each and every timo from scratch. 'To exemplify this, in the next section, the representation of leihen (in its variant to lend) is enriched by the lending person's belief in a return of the involved object.

\footnotetext{
${ }^{3} \operatorname{ref}(\mathrm{f}(\mathrm{x})): \mathcal{V} \rightarrow \mathcal{F} \rightarrow \mathcal{D}$. And $D$ is the set of reference objects.
}

\section{The Puzzle Fits}

Based on tho hypothesis that SF'I's prototypical situation descriptions can be interpreted in the sane way as Dliss we have proceeded to a new joined representation format. Since variables in a IBST have to be filled in by reference objects ancl, furthermore, the recursive application of instantiation rules provides variables of the same kind for events and statces, SW'l"s roference objocts and 1)R'T's discourse referents are rogarded as equivalent means of expression. 'Therefore, the joined representation format uses DRT's boxes. Ilowcver, it is enriched with, among others, a revised interface to syntax where the thematic roles are derived according to BSSEs.

The sample representations given in this section exploit. Kammp and Rofdentscher's idea of lexical axioms (cf. (Kannp and Robdentischer, 1994a); (Kamp and Robdeutscher, 1994b); (Robdeutscher, 1994)). Wo can distinguish in a parametric fashion between the semantic: components of the entries that characterize (partial) lexical fiekts and the concept specific information in the axioms.

'The first pair of axioms introduced below mir'. rors the fact that the configuration abbreviated by $e_{2}:\left(e_{21}, e_{22}\right)$ (cf. Figure 5) is suitable to specify a variety of lexical fields wherein the scmantics of the elements involves a special kind of 'change'. Some examples of these fields are change-of-place (e.g. to travel from one place to another), changeof-class (e.g. to promole somebody to a certain rank), and change-of-possession. Accordingly, wo propose a predicate hiemarchy, whereby the prodicates PlACE, ISA, IIAVJ; aro specializations of the predicate s'LA'T. Note, however, that this does not affect the mechanism of role derivation presented in section 3 .

In the prototypical situation description (cf. Higure 5), er inchudes $e_{21}$ and $e_{22}$. Wach of these denotes a 'TRANSIItION from an initial state to a final state, i.e., from init (e.2) and init. $\left(e_{22}\right)$ (tho presupposition) to fin $\left(e_{21}\right)$ and fin $\left(e_{22}\right)$ (the 
assertion). Because of the temporal identity of $e_{21}$ and $e_{22}$, there are temporal overlaps between the initial states as well as between the final states.

In the axiom defining CHANGE-SIGN's prestate, $s_{0}$ 's consequences $s_{1}$ and $s_{2}$ correspond to init $\left(e_{21}\right)$ and init $\left(e_{22}\right)$. In the axiom defining CHANGriSIGN's result state, $s_{0}$ 's consequences $s_{1}$ and $s_{2}$ correspond to fin $\left(e_{21}\right)$ and $f i n\left(e_{22}\right)$. The axioms have in common that they involve the concept CIIANGESIGN (cf. $e_{2}$ in Figure 5). The axioms are given in

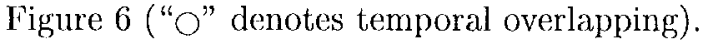

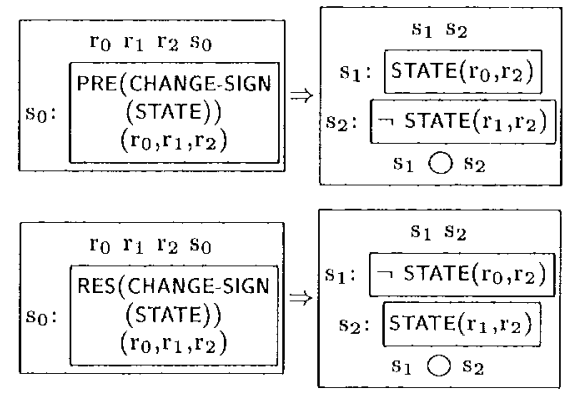

Figure 6. Axioms for CH $\Lambda$ NGE-SIGN.

The concepts defined by means of these axioms are, then, used to specify the lexical entry of verschenken (in its variant to give as a present). The thematic roles and the corresponding grammatical realizations result from the derivation presented in section 3. PRE(CHANGE-SIGN) delivers the first part of verschenken's presupposition. The parameter STATE is filled in by DISP\&OWN which is added to the predicate hierarchy sketched already as a specialization of the predicate IIAVF. Thereby, it is possible to distinguish between the pure disposal and the disposal that is accompanied by ownership.

Furthermore, verschenken's presupposition includes the semantic roles delivered by its prototypical meaning description. However, the selectional restrictions for discourse referents do not differ from the restrictions given in the prototypical situation description (cf. Figure 5). With respect to the semantic interpretation, each of source-have, goal-have, and locat-have just means is suitable as first argument in a HAVF-proposition. Generally, the predicate directly determines the selectional restrictions of its arguments, i.e., the discourse referents. Furthermore, for those predicates that take more than one argument, it is the order of the arguments which additionally determines the selectional restrictions. ${ }^{4}$

In accordance with the prototypical situation description given in Figure 5 the DRS for verschenken is as follows:

\footnotetext{
${ }^{4}$ Clearly, these are just two pieces of information for the selectional restrictions.
}

$$
\left[\begin{array}{cc}
\text { NOM } & \text { ec: verschenken } \\
<\text { agens, act }\rangle<\text { from }- \text { obj, have }\rangle & (\text { an }+ \text { goal, have }\rangle
\end{array}\right]
$$

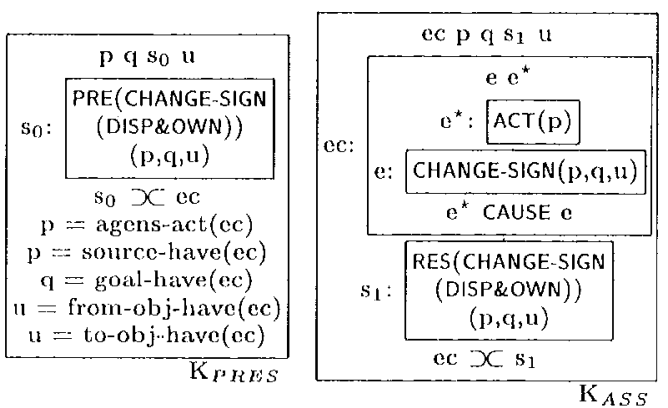

Figure 7. Lexical entry for verschenken.

Figure 8 clarifies the correspondences betweon DRT's and SET's representation:

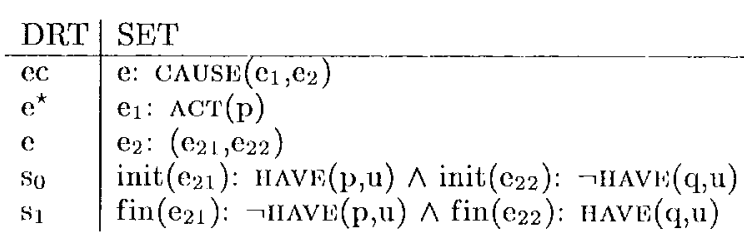

Figure 8. Relevant correspondences.

The entities constituting $e c$ (the action, the transitions, and the causation) are located in a common time span. Therefore, the transitions' initial states precede $e c\left(s_{0} \supset e c\right)$ and the transitions' final states follow ec (ec $\left.\supset s_{1}\right)$.

The lexical entry of leihen (in its variant to lend) consists of an interface list, whose thematic roles are based on SET, and of semantic structures, which include and extend verschenken's semantic components. The inferential behaviour of leihen (exemplified in section 2) motivates a formal description that contains more than the basic distinctions provided by the partial lexical field to give. Additionally, there is the lending person's belicf in a return of the involved object, in other words, the belief that the CHANGF-SIGN from $s_{0}$ to $s_{1}$ is temporary. Therefore, leihen's representations make use of CHANGE-SIGN's subconcept CIIANGE-SIGN-TEMP. This subconcept entails a transformation of its superconcept's prestate $s_{0}$ $\left(s_{0} \subsetneq e c\right)$ to its supcrconcept's poststate $s_{1}$ (ec $\left.\chi s_{1}\right)$ as well as the new poststate $s_{2}\left(e c \subsetneq s_{2}\right)$, i.e. the belief in a return of the involved object.

$$
\left[\begin{array}{ccc}
\text { NOM } & \text { DAT } & \text { ACC } \\
<\text { agens, act } & ><\text { goal, have }><\text { to }- \text { obj, have }>
\end{array}\right]
$$

Figure 9a. Interface list of leihen's entry.

To make the description of leihen complete, a further lexical axiom which explicitly notes the belief in a return of the involved object is needed. One of the formal means provided by DRT is the possibility to model components of psychological 
attitude states, e.g. beliefs or desires (cf. (FraCaSD8, 1994)).

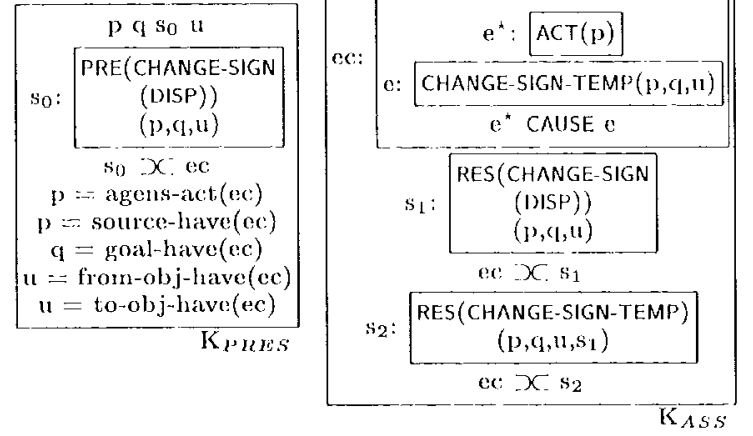

Figure 9b. Semantic structures of leihen's entry.

'This possibility can be used to state the axiom which represents the specific semantic contribution of CIINGE-SIGN-TEMP: its poststate characterized by the state $s_{2}$ of the person $r_{0}$ being in an psychological attitude state one of whose componcnts $(c)$ is a certain belicf. 'This belief consists of an inversed CIIANGF-SIGN-event e, i.c. a return, with its resulting disposal configuration $s_{3}$. Thereby, the former circumstances of disposal $s_{1}$, that result from the CIIANGE-SICNN-I'EMP-event itself, are supposed to abut on the return event $P$.

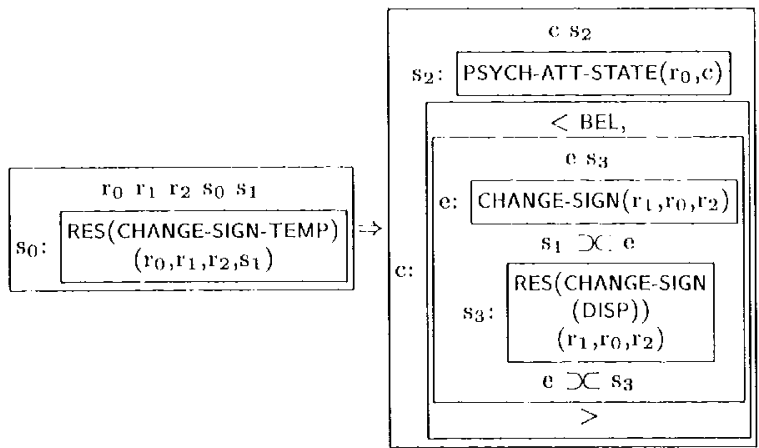

Figure 10. Axiom for CHANGE-SIGN-'I'EMP.

On the one hand, these results mark directions for the development of a comprehensive lexical theory, that includes, for example, an elaborated concept hierarchy with associated axioms. On the other hand, they can be used for a detailed reconstruction of the inferences mentioned in section 2 .

\section{Conclusion and Future Work}

In this article, we have first shown that it is sensible and promising to combine DRT's and SET's perspectives on lexical semantics. We made use of the theory-specific: strengths of the single approaches in order to overcome thoir specific weaknesses and to gain a powerful moans of expression for modelling the semantics of lexical entries. Second, we have proposed that and described how joined representations can be constructed by exploiting the merits of both theories.
Future work will concentrate on evaluating the benefits of this approach for computational text analysis. 'The joined representation format proposed here is likely to facilitate and improve lexical modelling as well as the automatic construction of text representations. Further investigattions in other lexical fields and word classess are required in order to achievo a larger lexical coverage. In correspondence with the theory-specific strengths, promising subtiasks will be reference resolution and the construction of conceptual representations.

\section{References}

Cooper, Robin ef al. 1994. Describing the $A p$ prouches. FraCaS. A Framework for Computational Semantics, Deliverable 8. Edinburgh, University of Fdinburgh: pp. 8-79.

Firzlaff, Beate and Jürgen Kunze. 1995. Automatic Generation of Lexical Fields. Working Papers of GMD, Report 892. St. Augustin, German National Research Conter for Information Technology.

Haenelt, Karin. 1994. Das 'Textanalyscsystem KON'TLX'I. Konzeption und Anwendungsmöglichkeiton. In Sprache und Datenverarbeitung, 18: pp. 17-31.

Hacnelt, Karin and Michael Könyves-Tóth. 1991. The Textual Development of Non-Stereotypic Concepts. In Proceedings of the 5 th Conference of the EACL. Berlin: pp. 263-268.

Jung, Uwo and Horbert Küstner. 1990. Semantische Mechanismen der Negation. studia grammatica xxxi. Berlin, Akademio Vorlag.

Kamp, IIans and Uwe Reyle. 1993. From Discourse to Logic. Dordrecht, Kluwer Academic Publishers.

Kamp, Hans and Antjo Roßdeutscher. 1994a. Remarks on Lexical Structure and DRS Construction. In Theoretical Linguistics, 20.2-3: pp. 97 164.

Kamp, Hans and Antje Roßdentscher. 1994b. DRS-Construction and Lexically Driven Infercnce. In Theorctical Linguistics, 20.2-3: pp. $165-235$.

Kunze, Jürgen. 1991. Kasusrelationen und Semantische Hmphase studia grammatica xxxii. Berlin, Akademie Verlag.

Kunze, Jürgen. 1993. Sememstrukturen und Feldstrukturen. studia grammatica xxxvi. Berlin, Akademic Verlag.

Roßßdeutscher, Antjo. 1994. Fat Child Mocts DRT. A Semantic Representation for the Opening Lines of Kaschnitr' "Das dicke Kind". In Theoretical Linguistics, 20.2-3: pp. 237-305.

Sandt, Rob A. van der. 1992. P'resupposition Projection as Anaphora Resolution. In Journal of Semantics, 9.4: pp. 333-377. 